\section{Protokoll der Mitgliederversammlung des Vereins Ultraschallmuseum e. V.}

am 24.9.2015 in Davos

Der Tagesordnung wird durch die Mitgliederversammlung zugestimmt.

1. Das Protokoll der Mitgliederversammlung DLT Innsbruck vom 30.10. 2014 wird einstimmig bestätigt.

2. Bericht des Vorstandes:

- 2015 veröffentlichte das Museum „50 Jahre Vidoson“ (Autor H. J. Holländer) und die Geschichte der DAUD, der Vorgängerin der DEGUM (Autoren H. Lutz und H. G. Trier) im Ultraschall in der Medizin/DEGUM Echo. 2016 wird nachfolgend dann die Geschichte der DEGUM publiziert.

- Zur Erweiterung des Bestandes wurde die komplette Sammlung von Prof. Trier (ophthalmologische Geräte) übernommen. Hierzu wurde die
Erweiterung des Regalsystems und der Ankauf einer Vitrine erforderlich. Die Sektion Ophthalmologie wird eingeladen, ihre Seminarleitertagung mal in Lennep abzuhalten.

- Leider hat Siemens die Spende von jährlich $2000 €$ eingestellt.

- Es wurden Gespräche geführt mit dem past Präsidenten der EFSUMB Christoph Dietrich über eine mögliche gemeinsame Arbeit über die Geschichte der Sonografie in Europa.

- Es wurde beschlossen, auf dem DLT in Leipzig 2016 das Museum gut zu präsentieren: Aufbau eines großen Industrietandes mit öffentlichem Vorschallen mit alten Geräten, ferner die ganztägigen Anwenderseminare mit einem historischen Rückblick zu beginnen (Genehmigung des DLT Präsidenten Prof Hagendorff liegt vor). Das Museum versucht noch, Siemens davon zu überzeugen, mit uns gemeinsam in einem Lunch-Symposium „50 Jahre Vidoson“ würdig zu feiern.

- Geräte: Von Prof. Trier wurden 8 Geräte, darunter 2 Compoundscanner beschafft, mit abenteuerlicher Ankopplung, (Ankopplung über Wasserbeutel). Des Weiteren ein funktionierendes B-Bild Gerät aus Bayern und ein Materialprüfgerät aus Berlin und ein ADR-Gerät

\section{Finanzbericht}

D B. Frentzel-Beyme stellt den Finanzbericht des Jahres 2014 vor und händigt ihn den Teilnehmern der MV aus. Kontostand: 6356,06€

> Entlastung des Vorstandes: Die Mitgliederversammlung entlastet einstimmig den Vorstand für seine Tätigkeit und den Finanzbericht 2014.

Protokoll: B. Frentzel-Beyme 